\title{
THE RELATIONSHIP OF MAXIMAL ALACTACID ANAEROBIC POWER TO SOMATOTYPE IN TRAINED SUBJECTS*
}

\author{
E. ERGEN, MD**, F. SARDELLA, MDt and A. DAL MONTE, MD†
}

**Sports Medicine Institute, Ege University, Bornova, Izmir, TURKEY

tSports Medicine Institute, CONI, Roma, ITALY

\section{ABSTRACT}

The purpose of the present study was to investigate the relationship between somatotype components and maximal alactacid anaerobic power (MAAP) in trained subjects. The somatotype components (endomorphy: $\bar{x}=2.66, S . D$. $= \pm 0.78 ;$ mesomorphy: $\bar{x}=5.45$, S.D. $= \pm 1.12$; ectomorphy: $\bar{x}=2.46, S . D .= \pm 0.88$ ) and total MAAP were measured in 40 male fencers (aged, $\bar{x} 21.79, S . D .= \pm 3.97$ ) in order to determine the correlations. The results did not show any correlations between the parameters. It can be concluded that the MAAP of an individual does not depend on the somatotype; but it may also be assumed that MAAP show changes with the percentage of fibre type, enzymatic activity in these fibres involved by large muscle groups which are relatively related to musculo-skeletal development (second component of somatotype) and neuro-muscular properties of the subjects, all having a genetic basis.

\section{INTRODUCTION}

Body size and the proportions, physique and body compositions have been observed and those characteristics of many sportsmen have long been accepted as important factors in the performance of strength and motor tasks (Malina, 1975; Schreiber, 1973). Anthropometrical dimensions have been related to work output, recognising their potential significance in influencing attained levels of performance. Anthropometry literally means the measurement of man (Malina, 1975). A considerable amount of information is available concerning the relationship of body structure and body composition to strength and performance. Heath and Carter (Carter, 1980) have defined the somatotype as a description of the present morphological conformation. The first component refers to as relative fatness, the second musculo-skeletal development and the third linearity. Muscle strength and speed of movement are quantities which cannot be separated in a discussion and closely related to the second component, theoretically (Laubach and McConville, 1969).

It has been known for some time that a possible relationship exists between muscle strength and hypertrophy; so that a higher muscle volume produces greater force output (Komi, 1979). An increase in the power due to muscle hypertrophy is accompanied by an increase in the weight (Kitagawa and Miyashita, 1978). Many of these investigations have been conflicting in nature, some authors reported highly significant correlations between anthropometry and muscle strength while others reported low correlations between the same dimensions. The extent to which such factors contribute to athletic performance is unclear, and in many cases they are probably secondary to factors such as strength levels, metabolic response traits, etc. (Thorland et al, 1981). Sheldonian somatotypes generally indicate negative relationships between endomorphy and performance (Malina, 1975). In relating anaerobic capacity to somatotype, it was demonstrated that increases in total lactate levels were observed only among the ectomorphs and power among mesomorphs and endomorphs. Tanner (1964) has found that activities characterised by power events favour participants with predominant musculo-skeletal development (Schreiber, 1973).

**Correspondence to:

Dr. Emin Ergen

Ege Medical Faculty

Sports Medicine Institute

Bornova, Izmir

TURKEY

*This study was completed at the Sports Medicine Institute, Italian National Olympic Committee.(CONI), Rome, Italy.
In recent years, it has become apparent that the performance in various physical activities is not only dependent upon an individual's typology, body composition and muscle mass, but also some ultrastructural properties such as muscle fibre composition, innervation and intracellular enzymatic activity which are all related to training and genetic factors.

Maximal alactacid anaerobic power is one of the most demanding performance tests which should play a role in the very early phase of maximal exertion in many sporting events. As the power is the function of muscle mass to exert force in a certain amount of time, so the muscle mass is an important factor for performance as a component of somatotype, especially mesomorphy which refers to relative musculo-skeletal development. The aim of this study was to investigate the relationship between the components of somatotype and MAAP.

\section{MATERIALS AND METHODS \\ Subjects}

40 male fencers whose ages ranged from 17.6 to $36(\bar{x}=$ 21.79, S.D. $= \pm 3.97$ ) years were examined in order to determine their somatotype and MAAP. All of these subjects were of regional and national standard.

\section{Somatotyping}

The anthropometrical measurements were taken by the same investigator. Morphological conformation was determined by utilising the Heath-Carter Anthropometric Somatotype Rating Method (Carter, 1980). Somatotype component scores were obtained with calculations which can produce an exact decimal rating based on the measurements provided:

$$
\begin{aligned}
& \text { Endomorphy }=-0.7182+0.1451(x)-0.00068\left(x^{2}\right)+ \\
& 0.0000014\left(x^{3}\right) \\
& \text { where } x=\text { sum of triceps, subscapular and supra- } \\
& \text { iliac skinfolds in } \mathrm{mm} \\
& \text { Mesomorphy }=[(0.858 \times \text { humerus breadth in } \mathrm{mm}+0.601 \\
& x \text { femur breadth in } \mathrm{mm}+0.188 \times \text { (arm } \\
& \text { girth-arm skinfold) in } \mathrm{cm}+0.161 \times \text { (calf } \\
& \text { girth-calf skinfold) in } \mathrm{cm} \text { ] } \\
& - \text { (height } \times 0.131)+4.5 \\
& \text { Ectomorphy }=(\text { Height-Weight Ratio }) \times 0.732-28.58 \\
& \text { if Height-Weight Ratio (HWR) }<\mathbf{4 0 . 7 5} \text { but } \\
& >38.25 \text {, then Ectomorphy }=\text { HWR } \times 0.463 \\
& -17.63 \\
& \text { and if HWR } \leqslant 38.25 \text { then rating of } 0.1 \text { is } \\
& \text { assigned }
\end{aligned}
$$


MAAP: The system proposed by Dal Monte et al (1978) was used in order to determine the MAAP and following formula was used for calculations:

$$
W=(a \times F x+b \times P)+E \times(P+F y)
$$

where W: total maximal alactacid anaerobic work (kgm/10 sec)

a: space covered in 10 seconds $(\mathrm{m})$

b: vertical elevation ( $m$ )

Fx: Horizontal component of strength $(\mathrm{kg})$

Fy: Vertical component of strength $(\mathbf{k g})$

$P$ : weight of the subject $(\mathrm{kg})$

$E$ : Energetic cost of running $=0.2964$ (by Cerretelli)

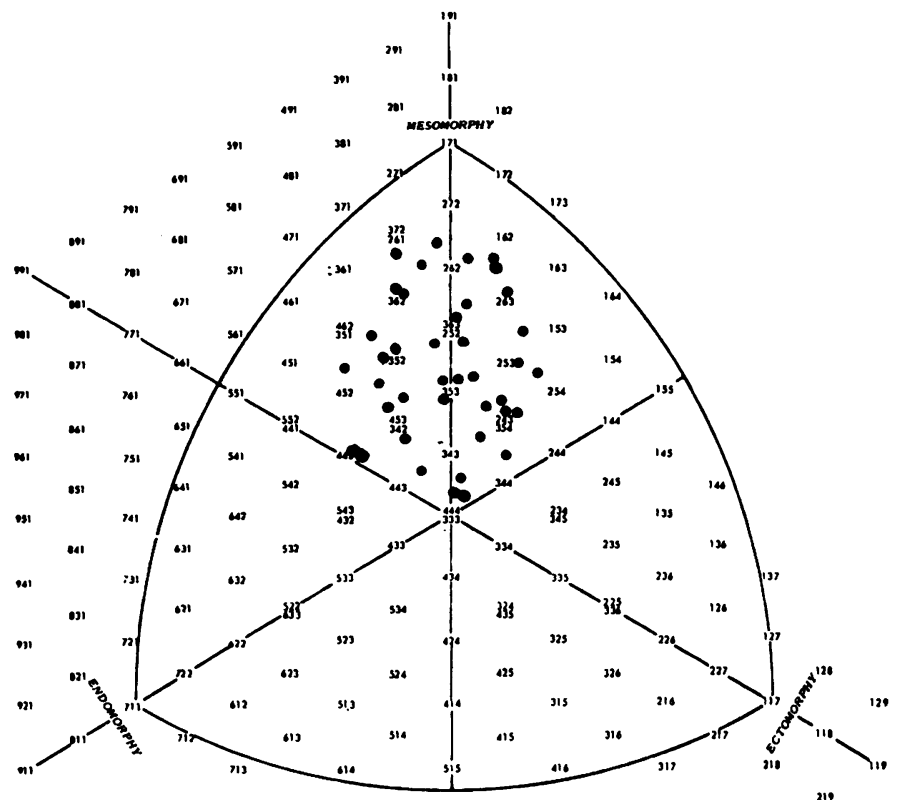

Fig. 1: Somatochart plotted with the values of the subjects.

Subjects were tested on a treadmill at the speed of 3 metres per second at an inclination of 10 per cent. The total work both in the first 2-4 seconds and 1-10 seconds were taken into account for calculations of correlations. The statistical analysis including the computation of mean values, standard deviations and correlations between parameters was done by means of a computer.

The measure of alactic anaerobic power:

The best known and most general method is Margaria's test. This test, where the curve expressing force/speed is considered, favours subjects who are capable of fast movement and thus a greater skill for obtaining the results, whereas those less agile and less rapid are probably penalised. To overcome such a limitation, a test which is based on the measure in $\mathrm{kgm} / \mathrm{sec}$ of maximal strength of a subject who walks and runs on a treadmill, at the same time pushing on a dynamometric bar which is in front of him at waist level was used. For the treadmill, the speeds of 1.5, 2 and 3 metres per second at an inclination of $10 \%$ have been chosen. Those were found appropriate for evaluations. In keeping with the time of exhaustion of alactic anaerobic energy sources, the duration of tests has been fixed at 10 seconds; all the other parameters, height of the bar in relation to the height of the subject, speed of the moving belt and inclination, have been previously verified. During the test, the subjects are asked to push the bar continuously and as hard as they could in the time fixed.

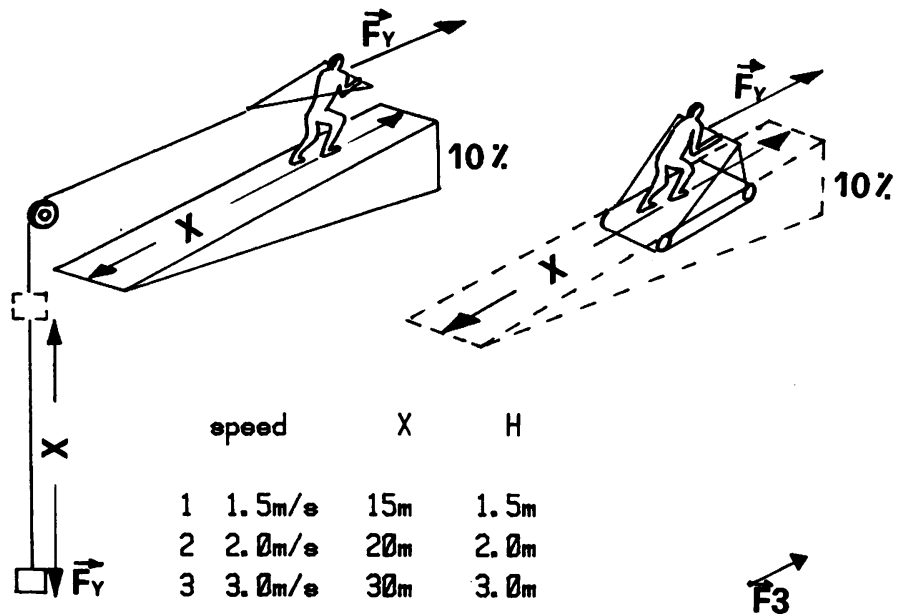

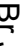

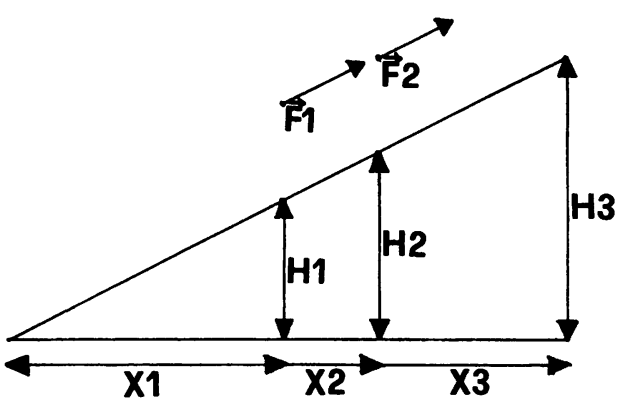

\section{RESULTS AND DISCUSSION}

The mean values and standard deviations of measurements of forty subjects were shown in Table I, and the correlation coefficients between somatotype components and MAAP in Table II. The somatochart presents the mean values of somatotype components of fencers (Fig. 1).

TABLE I

Mean values and standard deviations of subjects $(n=40)$

\begin{tabular}{lrc}
\hline & Mean & Standard Deviation ( \pm ) \\
\hline Age (years) & 21.79 & 3.97 \\
Height (cm) & 178.17 & 6.64 \\
Weight (kg) & 75.78 & 7.49 \\
Somatotype components & & \\
$\quad$ Endomorphy & 2.66 & 0.78 \\
$\quad$ Mesomorphy & 5.45 & 1.12 \\
$\quad$ Ectomorphy & 2.46 & 0.88 \\
MAAP (kgm/kg/sec) total & & \\
3 m/sec. $2-4 \mathrm{sec}$ & 1.13 & 0.17 \\
$3 \mathrm{~m} / \mathrm{sec} .1-10 \mathrm{sec}$ & 1.09 & 0.17 \\
\hline
\end{tabular}

TABLE \|

Correlation coefficients of parameters(r)

\begin{tabular}{lcc}
\hline & \multicolumn{2}{c}{ MAAP } \\
& $3 \mathrm{~m} / \mathrm{sec}, 2-4 \mathrm{sec}$ & $3 \mathrm{~m} / \mathrm{sec}, 1-10 \mathrm{sec}$ \\
\hline Endomorphy & 0.007 & 0.033 \\
Mesomorphy & 0.009 & 0.000 \\
Ectomorphy & 0.003 & 0.017 \\
\hline
\end{tabular}

According to the results, no correlations could be found between the somatotype components and MAAP. This was not surprising, because we also have found that no correlations between body composition and MAAP in a previous study. As the somatotype components refer to relative fatness, musculo-skeletal development and linearity, it may be assumed that there may be a relation between somatotype and body composition. 
On the other hand, some authors have reported low or moderate correlations between leg strength and mesomorphy (Laubach and McConville, 1969; Schreiber, 1973). But strength is not the only property which can cause relatively higher power output in a task. Power was found to be related to dynamic strength while velocity was related to speed, but only moderately related to explosive leg strength (Considine and Sullivan, 1973).

It has also been emphasised that the ultrastructural characteristics of muscle fibres involved by large muscle groups are of great importance when working predominantly short duration exercise (Clarkson et al, 1982; Gollnick, 1982; Howald, 1982; Komi, 1979). Training is considered as a factor improving the adenosine triphosphate (ATP) concentration in the skeletal muscle cells (Hermansenn, 1982). But training-induced transformation of type I to type II fibres is difficult to achieve (Howald, 1982) and also the amount of increased ATP in trained muscle is too small to present a significant storage of ATP for anaerobic use (Hermansenn, 1981). Fast twitch fibres (FT) can produce higher peak velocities and greater force output at a certain contraction velocity. It seems logical to assume that the form of the force:time curve in human muscle is influenced by relative proportion and absolute area of FT fibres (Kitagawa and Miyashita, 1978; Viitasalo and Komi, 1978).

Considering enzymatic activity muscle biopsies taken from the vastus lateralis muscle, have shown that the succinate dehydrogenase, hexokinase, aldolase, lactic dehydrogenase, phosphorylase and phosphofructokinase have great importance (Clarkson et al, 1982; Gollnick, 1982; Komi, 1979; Viitasalo and Komi, 1978). It has been shown that strenuous and brief exercise can be exerted better dependently upon the neuromuscular functions (Komi et al, 1978). FT fibres have a shorter electromechanical delay which is naturally controlled by the $\alpha$-motor neurons (Hermansenn, 1981; Komi, 1979). It is believed that traininginduced fibre transformation is difficult, because of the resting periods between training sessions of maximal exercise, the type I fibres will again be stimulated continuously by the typical low-frequency pattern of the slow motor neuron and this influence is much stronger than one imposed by short high-frequency bursts of stimulation during training (Komi, 1979). Therefore, the existence of major metabolic and functional differences between the different motor units in skeletal muscle has been shown to have a strong genetic basis (Viitasalo and Komi, 1978).

\section{CONCLUSION}

No correlations could be found between the somatotype components and maximum alactacid anaerobic power. And also the other observations concerning the magnitude of the correlations between the anthropometric dimensions and motor performance are generally low and best moderate. For all practical purposes they are not meaningfully predictive (Malina, 1975). In the view of the recent studies, MAAP may be related to neuromuscular function, intercellular enzymatic activity and fast-twitch fibre concentration which all have a strong genetic base.

\section{References}

Carter, J. E. Lindsay, 1980. The Heath-Carter Somatotype Method, Revised, A San Diego State University Syllabus, California.

Clarkson, P. M., Kroll, W., Graves, J. and Record, W. A., 1982 "The relationship of serum creatine kinase, fibre type and isometric exercise". Int.J. Sports Med. 3 (82): 145-148.

Considine, W. J. and Sullivan, W. J., 1973 "Relationship of selected tests of leg strength and leg power on college men". Res.Quar. 44 (4): 404-416.

Coyle, E. F., Costill, D. L. and Lesmos, G. R., 1979 "Leg extension power and muscle fibre composition". Med.Sci.in Sports 11 (1): 12-15.

Dal Monte, A., Leonardi, L. M. and Sardella, F., 1978 "The measure of anaerobic alactacid power in different sports". XXI FIMS World Congress of Sports Medicine, Brazil.

Gollnick, P. D., 1982 "Relationship of strength and endurance with skeletal muscle structure and metabolic potential". Int.J.Sports Med. 3 (82): 26-32.

Hermansenn, L., 1981 "Muscular fatigue during maximal exercise of short duration". Med.and Sci.in Sports $13(81)$ : 45-52.

Howald, H., 1982 "Training-induced morphological and functional changes in skeletal muscle". Int.J.Sports Med. 3 (82): 1-12.

Kitagawa, K. and Miyashita, M., 1978 "Muscle strength in relation to fat storage rate in young men". Eur.J.Appl.Physiol. 38 (78): 189-195.

Komi, P. V., 1979 "Neuromuscular performance: Factors influencing force and speed production". Scand.J.Sports Sci. 1 (79): 1, 2-15.

Komi, P. V., Viitasalo, J. T., Raurama, R. and Vihko, V., 1978 "Effects of isometric strength training on mechanical, electrical and metabolic aspects of muscle function". Eur.J.Appl.Physiol. 40 (78): 45-55.

Laubach, L. L. and McConville, J. T., 1969 "The relationship of strength to body size and typology". Med.and Sci.in Sports 1 (4): 189-194.

Malina, R. M., 1975 "Anthropometric correlates of strength and motor performance". Exercise and Sports Sciences Review (ed. Wilmore, J. H. and Keogh, J. F.) Vol. 3, Academic Press, New York 249-274.

Schreiber, M. L., 1973 "Anaerobic capacity as a function of somatotype and participation in varsity athletics". Res.Quar. 44 (2): 197-205.

Tanner, J. M., 1964. The Physique of the Olympic Athlete. George Allen and Unwin, London.

Thorland, W. C., Johnson, G. O., Fagot, T. G., Thorp, G. D. and Hammer, R. W., 1981 "Body composition and somatotype characteristics of junior Olympic athletes". Med.and Sci.in Sports 13 (5): 332-338.

Viitasalo, J. T. and Komi, P. V., 1978 "Force-time characteristics and fibre composition in human leg extensor muscles". Eur.J.Appl.Physiol. 40 (78): 7-15. 